\title{
The adaptive response of bacterial food-borne pathogens in the environment, host and food: Implications for food safety
}

\author{
Avelino Alvarez-Ordóñez ${ }^{a}$, Véronique Broussolle ${ }^{\mathrm{b}, \mathrm{c}}$, Pierre Colin ${ }^{\mathrm{d}}$, Christophe Nguyen-The ${ }^{\mathrm{b}, \mathrm{c}}$, Miguel Prieto ${ }^{\mathrm{e}, *}$ \\ a Teagasc Food Research Centre, Moorepark, Fermoy, Co. Cork, Ireland \\ b INRA, UMR408 Sécurité et Qualité des Produits d'Origine Végétale, F-84000 Avignon, France \\ c Univ-Avignon, UMR408 Sécurité et Qualité des Produits d'Origine Végétale, F-84000 Avignon, France \\ d University of Brest, Technopôle Brest-Iroise, Plouzané, France \\ e Department of Food Hygiene and Technology, University of León, León, Spain
}

\begin{abstract}
A B S T R A C T
Bacteria are constantly faced to stress situations in their ecological niches, the food and the host gastrointestinal tract. The capacity to detect and respond to surrounding changes is crucial for bacterial pathogens to survive or grow in changing environments. To this purpose, cells have evolved various sophisticated networks designed to protect against stressors or repair damage caused by them. Challenges can occur during production of foods when subjected to processing, and after food ingestion when confronted with host defensive barriers. Some pathogenic bacteria have shown the capacity to develop stable resistance against extreme conditions within a defined genomic context and a limited number of generations. On the other hand, bacteria can also respond to adverse conditions in a transient manner, through the so-called stress tolerance responses. Bacterial stress tolerance responses include both structural and physiological modifications in the cell and are mediated by complex genetic regulatory machinery. Major aspects in the adaptive response are the sensing mechanisms, the characterization of cell defensive systems, such as the operation of regulatory proteins (e.g. RpoS), the induction of homeostatic and repair systems, the synthesis of shock response proteins, and the modifications of cell membranes, particularly in their fatty acid composition and physical properties. This article reviews certain strategies used by foodborne bacteria to respond to particular stresses (acid, cold stress, extreme pressure) in a permanent or transient manner and discusses the implications that such adaptive responses pose for food safety.
\end{abstract}

Keywords:

Adaptive response

Stress

Mutation

SPANC

Cold

Acid

Salmonella

Bacillus cereus

\section{Introduction}

Foods are complex environments in which microorganisms may face natural stress conditions such as limited nutrient availability, adverse $\mathrm{pH}$, osmolarity, oxidation, and extreme temperatures, among others. In addition, industrial food preservation regimes commonly rely upon imposing extreme physical and chemical stresses with the aim to inactivate or limit the growth of pathogenic bacteria. Thus, a variety of preservation technologies such as thermal processing, high hydrostatic pressure, pulsed electric fields, radiation, refrigeration, drying, etc. impose a challenge to bacterial cells and can determine the fate of food-borne pathogens along the food chain. Modern strategies in food preservation seek to use mild treatments that inhibit permanently stressed or injured microorganisms by using multiple barriers, especially in the case of minimally processed foods. However, cells adapted to stress, hardened, could be able to withstand further treatments or even the passage through the stomach and intestinal barriers when confronted with host defensive barriers. Other concern is represented by the difficulty of detection during the microbiological

\footnotetext{
* Corresponding author
}

analysis of injured cells because they are not able to grow in conventional microbiological media, when inhibitory compounds are used or an appropriate environment for resuscitation is absent. In this regard, the situation could lead to an overestimation of the lethality of treatments, or to the failure in the detection of pathogens during routine quality control of foods or outbreak investigations.

Bacteria have evolved a range of adaptive strategies to cope with rapidly changing environmental conditions and ensure their survival in inhospitable niches. The stress responses are global, complex systems of defence. They comprise networks to adapt to changing environments and to survive under adverse conditions. Adaptations sometimes derive from the acquisition of stochastic genomic mutations which are positively selected and fixed in the microbial population due to the beneficial phenotype they confer under selective pressure environments (Rando and Verstrepen, 2007). In other occasions, a transient stress response generally consisting of a characteristic change in the pattern of gene expression occurs (Abee and Wouters, 1999). Bacteria are able to do so by upregulating certain genes and down regulating others in order to maintain viability. If the environment surrounding the cell is modified, the changing conditions are sensed by the cell, and the adaptive response is triggered. The genetic regulation involves a series of 
switches controlling the coordinated expression or repression of genes. In the end, a series of physiological responses occur with changes in proteins, DNA, lipids, etc. The response includes the initiation of homeostatic systems, induced synthesis of stress proteins which repair damaged DNA and proteins, and activation of enzymatic systems with specific stress-counteracting activities. Transient stress responses can also occur through modulation of the envelopes and other cellular structures to keep functionality. These transient stress responses help to protect vital processes and to restore cellular homeostasis, to repair the damage, to counteract or eliminate the stress agent, and/or to increase the cellular resistance against subsequent stress challenges.

\section{Acquisition of permanent stress tolerance through adaptive mutagenesis}

The known edges of the biosphere are typically delineated by extremophilic bacteria that manage to resist the severe physical and chemical conditions encountered in these environments. However, further to the existence of extremophiles, some mesophilic bacteria have shown the capacity to develop resistance against extreme environments within a defined genomic context and a limited number of generations, in a clear example of bacterial adaptability (Vanlint et al., 2011). Such adaptability could be the basis for the existence or persistence of classic mesophilic bacteria in extreme environments that so far have been reported as inaccessible by current experimental techniques.

High hydrostatic pressure (HHP) processing is becoming a valuable non-thermal food pasteurization technique. While the degree of natural HHP resistance has already been shown to vary greatly among and within bacterial species, a still unresolved question remains as to what extent different food-borne pathogens can actually develop HHP resistance, and how this impacts food safety of HHP processed products. Vanlint et al. (2011) used a direct evolution approach to assess the potential of the mesophilic model bacterium Escherichia coli to acquire stable resistance to extreme high temperatures or pressures. They observed that while heat resistance could only marginally be increased, piezoresistance (i.e. resistance to high pressures) could readily and reproducibly be extended into the Gigapascal range. The currently recognized maximum pressures for growth or survival of any vegetative microorganisms (including E. coli) are in the range of $120 \mathrm{MPa}$ and 800-900 MPa, respectively (Zeng et al., 2009; Jofré et al., 2010). Indeed, it was generally assumed that vegetative microorganisms would never be able to survive exposures in the GPa range (Daniel et al., 2006). However, in the study by Vanlint and co-workers the acquired piezotolerance was extraordinary, since the upper pressure limit for survival increased from the initial $600 \mathrm{MPa}$ to $2 \mathrm{GPa}$, thereby greatly exceeding the currently recognized maximum high pressure for growth or survival, and the pressure levels commonly used in food industries for food preservation.

Acquisition of extreme piezotolerance among food-borne pathogens might not be limited to E. coli. Vanlint et al. (2012) examined the potential for HHP resistance development among strains of E. coli, Shigella flexneri, Salmonella Typhimurium, Salmonella Enteritidis, Yersinia enterocolitica, Aeromonas hydrophila, Pseudomonas aeruginosa and Listeria innocua and reported that extreme HHP resistance was only observed in some E. coli strains. These authors concluded that a specific genetic predisposition could be required for HHP resistance development. However, piezotolerant variants have been found by other research groups in other food-borne pathogens such as Listeria monocytogenes and Staphylococcus aureus (Karatzas and Bennik, 2002; Karatzas et al., 2005, 2007; Van Boeijen et al., 2010). In the study by Karatzas and Bennik (2002) a piezotolerant strain of $L$. monocytogenes was isolated after a single HHP treatment of $400 \mathrm{MPa}$ for $20 \mathrm{~min}$. This isolate showed morphological alterations, including increased cell size and lack of flagella and also presented increased stress tolerance to heat, acid and hydrogen peroxide treatments. This resistant phenotype was attributed to a single codon deletion in a glycine-encoding repeat region of the $c t s R$ gene, which encodes a class 3 heat shock response regulator. In a subsequent study Karatzas et al. (2005) exposed wild type cultures of L. monocytogenes EGDe to $350 \mathrm{MPa}$ for $20 \mathrm{~min}$ and evaluated the piezotolerance of individual surviving isolates, finding 33 isolates with a stable piezotolerant phenotype. Interestingly, 21 of these 33 piezotolerant variants had mutations in the ctsR gene. These mutations mainly consisted of deletions or codon insertions in the glycine repeat region of the ctsR gene. However, a piezotolerant phenotype could not be linked to mutations in the ctsR gene for the rest of variants, which evidenced that other unknown mechanisms may also lead to stable piezotolerance in L. monocytogenes. Similarly, Van Boeijen et al. (2010) isolated 24 L. monocytogenes LO28 stress-resistant variants after HHP treatment. Genetic analysis of these variants revealed two variants with deletions in the upstream region of $c t s R$ and seven variants with mutations in the ctsR gene itself. Interestingly, all variants were more resistant to heat than the wild type strain. Piezotolerant variants have been also found for S. aureus by Karatzas et al. (2007) following a HHP treatment of a clonal culture at $400 \mathrm{MPa}$ for $30 \mathrm{~min}$. The majority of these isolated variants showed increased thermotolerance, impaired growth and reduced antibiotic resistance as compared to the wild type. However, no mutations in the ctsR gene were detected for any of the variants, which suggests that genes and regulatory mechanisms involved in acquisition of resistance to HHP by S. aureus may differ from those of L. monocytogenes.

Selection of resistant variants has been also reported for certain food-borne pathogens after exposure to other stress conditions or food processing technologies different to HHP. Van Boeijen et al. (2011) isolated highly heat-resistant variants for two strains of L. monocytogenes by using a kinetic modelling-based sampling scheme. Interestingly, they revealed for one of these strains the presence of heatresistant variants under industrially relevant conditions, i.e. through growth in ultra-high temperature (UHT)-processed whole milk followed by heat treatment cycles at $72{ }^{\circ} \mathrm{C}$. Variants thus obtained showed high resistance to standard pasteurization conditions. Several of the highly heat-resistant variants had also mutations in the ctsR gene, while the mechanisms leading to increased resistance in the rest of variants were not elucidated. Karatzas et al. (2008) showed that exposure of cells of $S$. Typhimurium and $S$. Enteritidis to extreme acid environments ( 15 cycles of exposure to $\mathrm{pH} 2.5$ for up to $4 \mathrm{~h}$ followed by growth at $\mathrm{pH} 7.0$ for $48 \mathrm{~h}$ ) gave rise to an increase in the population acid resistance by three to four fold. In addition, these authors isolated from those acid-exposed populations variants with a stable increased acid resistance, which also showed increased heat resistance, reduced virulence and changes in colony morphology, expression of fimbriae, and growth. Moreover, stable highly acid resistant variants of $L$. monocytogenes have been recently isolated by Metselaar et al. (2013) after exposure of lateexponential phase cells to $\mathrm{pH} 3.5$ for $90 \mathrm{~min}$. Sixteen of the twenty-three variants isolated by these authors were highly resistant to a treatment at $\mathrm{pH} 2.5$ for $3.5 \mathrm{~min}$, showing less than $1 \log$ reduction after acid treatment, compared to an average of 4 log reductions for the wild type strain. Nevertheless, the genetic shifts behind the acquisition of stable extreme acid resistance in these bacterial populations have not been unravelled yet.

\section{Transient adaptive responses to stress}

Apart from the above discussed stable and selection-driven acquisition of high resistance to stress, microorganisms can respond to adverse conditions in a transient manner, i.e. once the stressor disappears the bacterial population recovers its conventional tolerance to the particular stress agent. A good example of a transient response to stress are the stress tolerance responses, which can be defined as the induced resistance to normally lethal stress conditions following growth or short-term exposure at mild sub-lethal stress conditions. Stress tolerance responses are commonly mediated through activation of particular 
Version définitive du manuscrit publiée dans / Final version of the manuscript published in :

International Journal of Food Microbiology (2015), Vol. 213, p. 99-109, DOI: 10.1016/j.ịfoodmicro.2015.06.004

Journal homepage : http://www.elsevier.com/locate/ijfoodmicro

response regulators which control the expression of specific sets of genes and orchestrate very complex responses involving the induction of cellular enzymes, the synthesis of stress-shock proteins that protect or repair cellular proteins and DNA, and the modulation of the composition and physical properties of the cellular envelopes. The next section of the review article will focus on two of the most well-studied stress tolerance responses with an impact on food safety, the acid tolerance response of $S$. Typhimurium and the cold adaptation response of Bacillus cereus. S. Typhimurium and B. cereus were selected as major foodborne pathogens representative of distant phylogenies (Salmonella as a Gram-negative non-spore former and B. cereus as a Gram-positive spore-former) which molecular mechanisms of response to foodrelated stresses have been intensively studies in the last decades.

\subsection{The acid tolerance response of S. Typhimurium}

The acid tolerance response (ATR) of S. Typhimurium can be defined as the induced resistance to normally lethal low $\mathrm{pH}$ following growth at moderately low $\mathrm{pH}$, or following short-term exposure to mild acid conditions. In the last two decades, numerous studies have emerged describing the complex molecular mechanisms involved in S. Typhimurium ATR, the influence of different environmental parameters and the relationships between $S$. Typhimurium ATR and virulence. In addition, studies have also shown the existence of similar adaptive responses for other Salmonella enterica serovars (reviewed by Alvarez-Ordóñez et al., 2012b).

\subsubsection{Homeostatic systems}

Gram-negative microorganisms keep intracellular $\mathrm{pH}$ relatively constant at $\mathrm{pH} 7.6$ to 7.8 , even as external $\mathrm{pH}$ changes during growth (Foster, 2000). A stable intracellular pH is maintained by pumps (potassium-proton antiporters and sodium-proton antiporters) which extrude protons from cytoplasm at low pH environments (Foster, 2000). Furthermore, it has recently become clear that inducible lysine decarboxylase and arginine decarboxylase systems play an important role in the maintenance of intracellular $\mathrm{pH}$ in $S$. Typhimurium (Fig. 1) (Kieboom and Abee, 2006; Álvarez-Ordóñez et al., 2010b). The role of these latter homeostatic systems in protecting the cell against stress is further discussed in subsequent sections of the manuscript (Section 4. Using food components to survive under harsh conditions).

\subsubsection{Acid shock proteins}

Several groups of acid shock proteins (ASP's) are induced during $S$. Typhimurium ATR in order to prevent or repair the macromolecular damage caused by acid stress (Audia et al., 2001). An extensive research effort has been made in the last decades to identify and characterize these stress proteins in $S$. Typhimurium and several regulatory genes controlling the expression of different subsets of ASP's have been described, including the alternative sigma factor RpoS, the iron regulator Fur, the two-component signal transduction system PhoP/PhoQ and the OmpR response regulator (Fig. 1) (Foster, 2000). Most of the identified ASP's are involved in cellular regulation, molecular chaperoning, energy metabolism, transcription, translation, synthesis of fimbriae, regulation of the cellular envelopes, colonization and virulence (Bearson et al., 2006).

\subsubsection{Membrane fluidity}

The cellular envelopes are the first barrier of defence of microorganisms against the stressful environmental conditions they face. Consequently, modulation of composition and physical properties of the main components of the cellular envelopes, the cytoplasmic membrane and the cell wall, plays an important role when counteracting the odds of an acid environment. As an adaptive mechanism to acid stress, bacteria can change their membrane composition with the purpose of maintaining a degree of membrane fluidity compatible with life (Fig. 1) (Beney and Gervais, 2001). Interestingly, a number of studies have suggested a relationship between membrane fluidity and stress tolerance (de Jonge et al., 2003; Alvarez-Ordóñez et al., 2008, 2010a). It is for instance well studied the impact that variations in membrane fatty acid composition and membrane fluidity in response to changing growth conditions have on bacterial tolerance to heat treatments. Several studies agree in the fact that reduced membrane fluidity is linked to enhancements in heat resistance and vice versa (Annous et al., 1999; Sampathkumar et al., 2004; Alvarez-Ordóñez et al., 2008, 2009a). $S$. Typhimurium cells grown at acid $\mathrm{pH}$ undergo a membrane adaptation characterized by a decrease in the unsaturated to saturated fatty acid ratio and in the relative concentration of octadecenoic (oleic or vaccenic) acids (C18:1), with a concomitant increase in the content in cyclic fatty acids, mainly methylenoctadecenoic (dihydrosterculic or lactobacillic) acids (cyc19). These changes in membrane composition resulted in cells which in general showed a higher ability to survive to

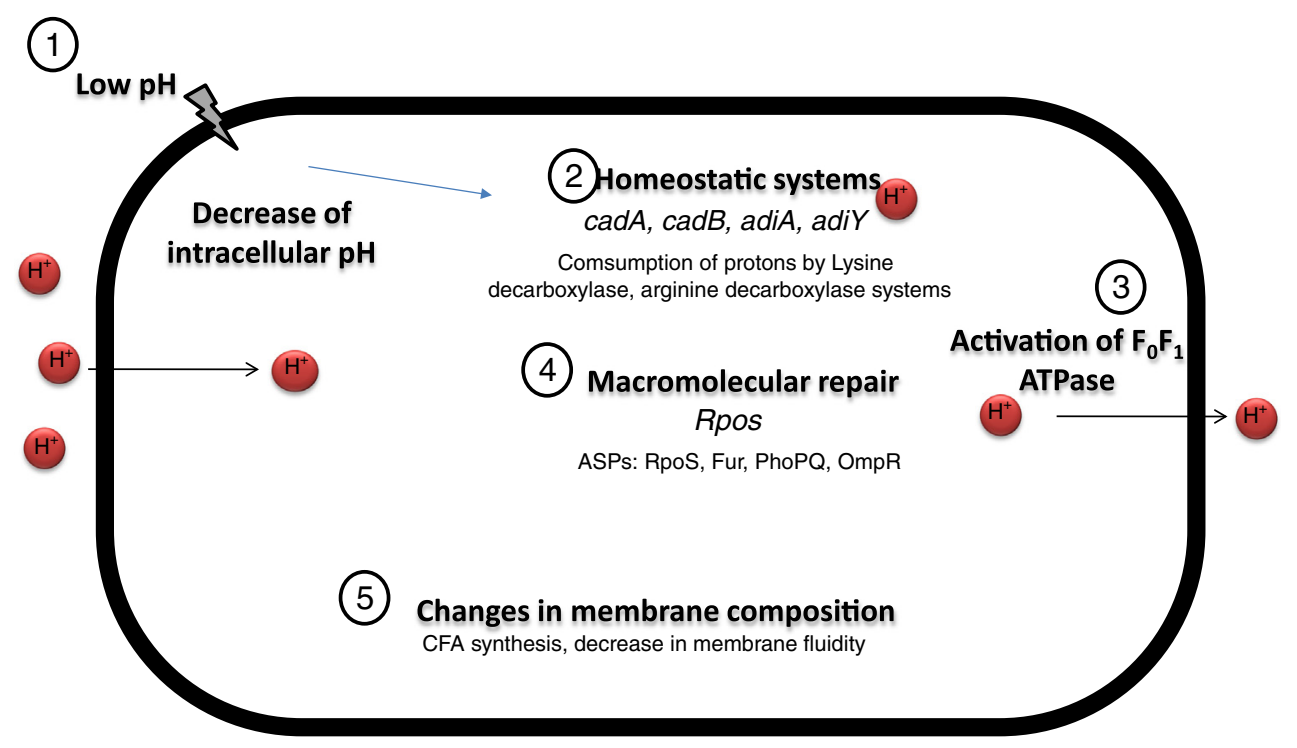

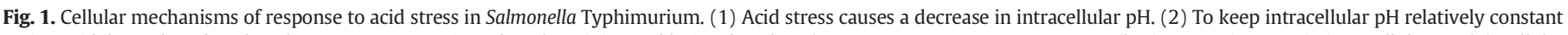

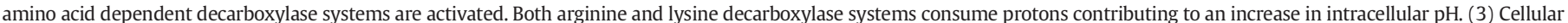

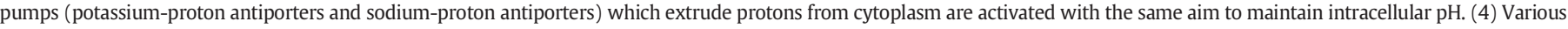

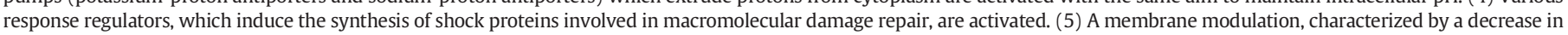
the unsaturated fatty acids content and in membrane fluidity and an increase in cyclopropane fatty acids, takes place. 
lethal acid and heat treatments (Alvarez-Ordóñez et al., 2008, 2009b). The actual effect that such changes in membrane composition occurring in response to acid $\mathrm{pH}$ have on the cellular membrane fluidity were subsequently monitored by Fourier transform infrared spectroscopy (Álvarez-Ordóñez et al., 2010a). The vibrational modes of the acyl chain $v s \mathrm{CH}_{2}$ symmetric stretching band, which are indicators of bacterial membrane fluidity, were assessed after growth of $S$. Typhimurium and $\mathrm{S}$. Enteritidis in acidic media at different $\mathrm{pH}$. Results obtained evidenced that cells grown in acidified media showed a reduction in their membrane fluidity.

Exposure to different sorts of stress have been shown to cause the conversion of a significant proportion of the membrane unsaturated fatty acids to their cyclic derivatives, known as cyclopropane fatty acids (CFAs). The CFAs are formed by a CFA synthase (encoded by the cfa gene), predominantly as cultures enter into the stationary-phase (Grogan and Cronan, 1997). Kim et al. (2005) suggested for the first time that the formation of CFAs in the membrane may be a major factor that protects $S$. Typhimurium from lethal stress exposures, including acid stress. Although the contribution of CFAs to bacterial membrane properties is not fully understood, it has been hypothesized that the presence of a cyclopropane ring within membrane FAs increases the stability of the structural and dynamic properties of biological membranes and restricts the overall mobility and disorder of the acyl chains, thus decreasing the membrane fluidity (Duforc et al., 1984; Grogan and Cronan, 1997). Other authors have postulated that the primary function of CFAs formation is to change chemical rather than physical properties of the membrane. As an example, CFAs appear to be considerably less reactive than the corresponding unsaturated FA towards certain forms of oxidation (Grogan and Cronan, 1997), which suggests that CFAs exert their protective effect against lethal stress exposures through reduction of cellular oxidative damage. Finally, the cyclization of membrane FAs has been also proposed as a means of controlling the penetration of undesirable molecules from the cellular surroundings (Chang and Cronan, 1999).

\subsection{The cold adaptation response of B. cereus}

The food-borne pathogen B. cereus produces heat resistant spores and is an important hazard for heat-treated, non-sterilized, foods. In addition, some $B$. cereus strains are psychrotrophic and may grow in refrigerated foods. The cold adaptation of $B$. cereus makes it one of the few pathogens able to survive food processing and to multiply in cooked-chilled foods (Stenfors Arnesen et al., 2008).

\subsubsection{Membrane fluidity}

Low temperatures reduce membrane fluidity of bacteria and in particular of B. cereus (De Sarrau et al., 2012). To maintain membrane functions, bacteria adapt by increasing in their membrane the proportion of fatty acids with lower melting points, such as unsaturated fatty acids (Mansilla et al., 2004). In the case of B. cereus, the main changes in fatty acids composition caused by growth at low temperature are a decrease of the branched, saturated fatty acids iso- $\mathrm{C}_{15}$ and iso- $\mathrm{C}_{17}$, with a concomitant increase in the branched saturated fatty acid iso- $\mathrm{C}_{13}$ and in the branched, monounsaturated fatty acid iso- $\mathrm{C}_{17}: 1$ (Haque and Russell, 2004; Brillard et al., 2010; De Sarrau et al., 2012), unsaturated in position 5 (De Sarrau et al., 2012) (Fig. 2a). Globally, B. cereus adapts to cold by increasing markedly the ratio of unsaturated/saturated fatty acids (Haque and Russell, 2004; Brillard et al., 2010; De Sarrau et al., 2012) which gives to the membrane of cold adapted B. cereus the same fluidity at cold temperature as the membrane of non-adapted B. cereus at optimal temperature (De Sarrau et al., 2012). Some bacteria, in particular Bacillus subtilis, can also adapt to cold temperature by increasing the ratio of anteiso versus iso branched chain fatty acids (Beranova et al., 2010). Haque and Russell (2004) also noted an increase in the anteiso/iso ratio upon growth at low temperature of $B$. cereus, but this was not observed by De Sarrau et al. (2012) and Brillard et al.
(2010). In these three studies on B. cereus, anteiso fatty acids were in much lower proportion than iso fatty acids, in contrast to the results on B. subtilis by Beranova et al. (2010). B. cereus produces two acyllipid desaturases, DesA and DesB, creating double bounds in the fatty acid chain in respectively positions 5 and 10 (Cifre et al., 2013). As at cold temperature $B$. cereus mostly accumulate fatty acids unsaturated in position 5 , DesA has presumably the main role in cold adaptation of B. cereus (Fig. 2a). These acyl-lipid desaturases are not active in absence of oxygen (Beranova et al., 2010) which explains that B. cereus was not able to produce unsaturated fatty acids in anaerobiosis (De Sarrau et al., 2012). As a consequence, anaerobiosis markedly hampered cold adaptation of B. cereus (De Sarrau et al., 2012), suggesting that association of anaerobic packaging and cold storage of foods might reduce the risk of $B$. cereus development. The mechanisms responsible for the increase of the iso $\mathrm{C}_{13} /$ iso $_{15}$ ratio at cold temperature are not fully understood. A lipase of the GDSL (Gly-Asp-Ser-Leu) family, characterized by an amino acids signature motif, presumably has an important role (Fig. 2a) because the mutant deleted for the corresponding lipase gene showed a reduced growth at low temperature with no changes in the iso $\mathrm{C}_{13} /$ iso $\mathrm{C}_{15}$ ratio, while the unsaturated fatty acids increased as in the wild type strain (Brillard et al., 2010).

\subsubsection{Translation}

Low temperatures stabilize mRNA secondary structures, thereby reducing translation efficiency. Many bacteria respond by synthesis of RNA helicases, enzymes that unwind in vitro unfavourable secondary mRNA structures using ATP as energy source (Cordin et al., 2006; Iost and Dreyfus, 2006), participate in ribosome biogenesis (Charollais et al., 2004) and degrade mRNAs through a multi-proteins complex, the degradosome (Hardwick and Luisi, 2013). Several RNA-helicases are usually present in bacteria, with different roles in cold adaptation. B. cereus possesses 5 RNA-helicases, CshA, CshB, CshC, CshD and CshE, all over-expressed at cold temperature (Pandiani et al., 2010) but with only CshA, B, and C being necessary for cold adaptation (Pandiani et al., 2010). Deletion mutants showed that CshA and CshC had the strongest impact on cold adaptation, followed by CshB. Cold growth of a mutant deleted for CshA was partially restored by complementation with CshB, indicating overlapping mechanisms between these two RNA-helicases, but not with CshC (Pandiani et al., 2010). In B. cereus deletion of CshA reduced growth rate at all temperatures except those close to the maximum growth limit. Deletion of CshB reduced growth rates at temperatures below and above the optimum for growth, while deletion of CshC reduced growth only below the optimum temperature (Pandiani et al., 2011). In addition the three helicases contributed to adaptation to oxidative conditions and CshA to adaptation to basic pH (Pandiani et al., 2011). Although the strongest impact of deleting the RNA-helicases CshA, B and C was on cold adaptation with absence of growth at low temperatures, they presumably have a wider role in adaptation to various conditions. Whether this ubiquitous role of RNA-helicases is important for cross adaptation to various stresses is not known. Cold shock proteins, among the first proteins synthetized by bacteria upon cold-shock, also interact with folded mRNA to permit an efficient translation at low temperatures, some in cooperation with RNA-helicases (Hunger et al., 2006). Two of the five cold shock proteins identified in B. cereus (CspA and CspE) increased after cold-shock (Mayr et al., 1996) indicating that this mechanism is presumably also present in B. cereus.

\subsubsection{Proteins misfolding}

Deletion of a gene coding for a Clp protease (clpP1) hampered growth below the optimum temperature of Bacillus thuringiensis (Fedhila et al., 2002), a very close relative of B. cereus. Clp protease can have a role in preventing polypeptides misfolding, a possible consequence of low temperatures. 
Version définitive du manuscrit publiée dans / Final version of the manuscript published in :

International Journal of Food Microbiology (2015), Vol. 213, p. 99-109, DOI: 10.1016/j.ijfoodmicro.2015.06.004

Journal homepage : http://www.elsevier.com/locate/ijfoodmicro

a

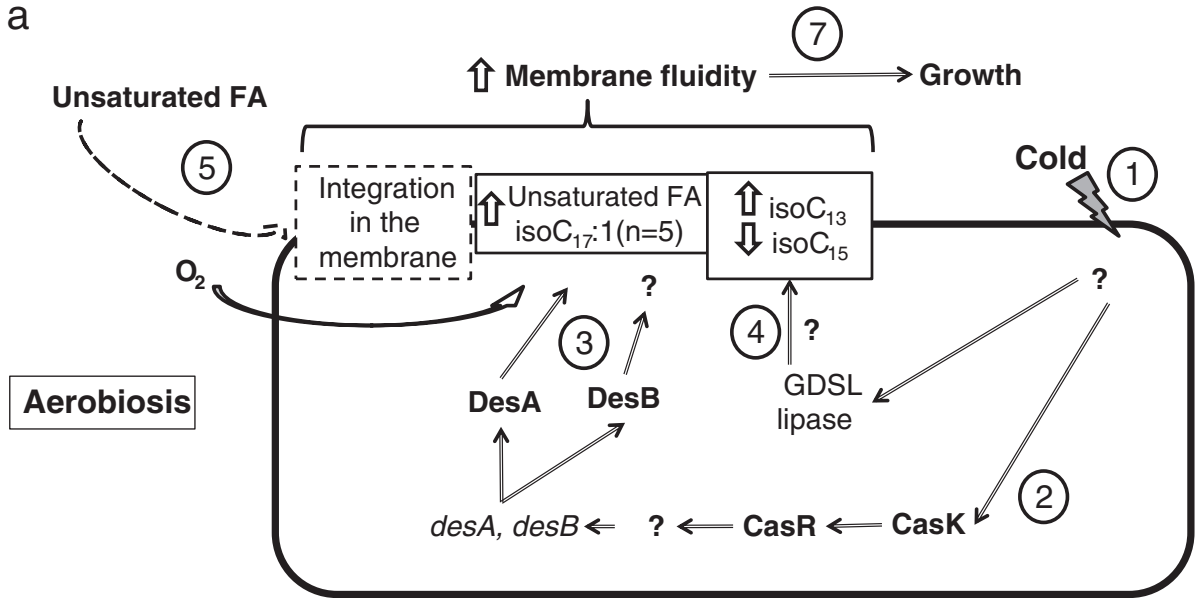

b

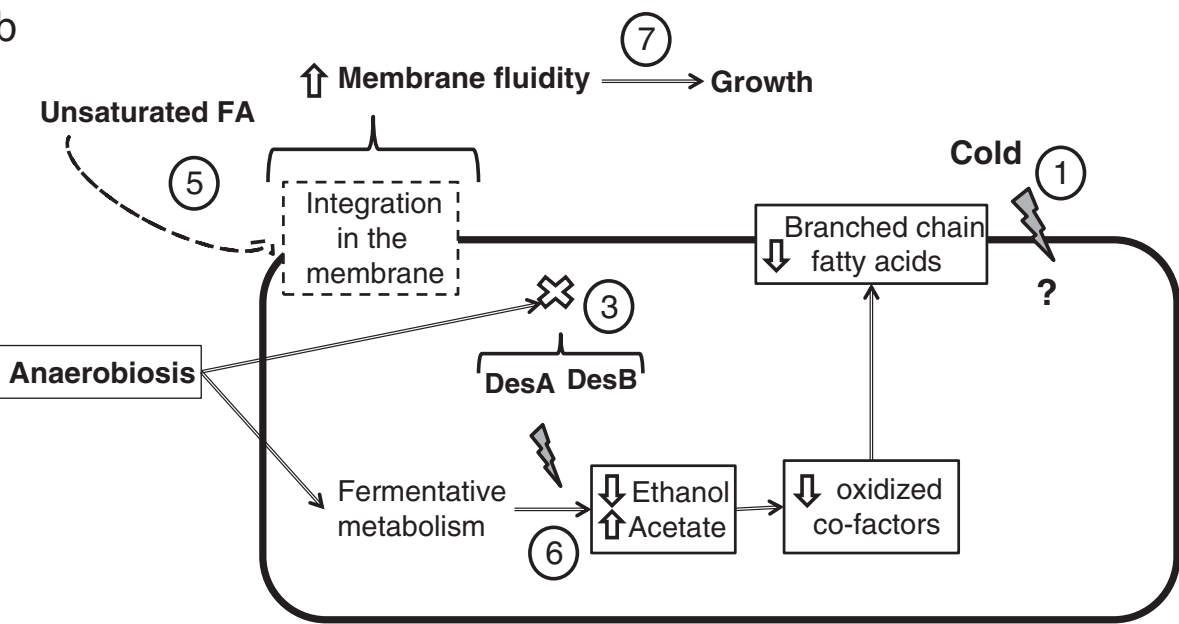

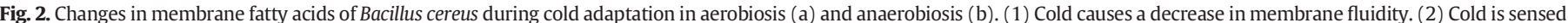

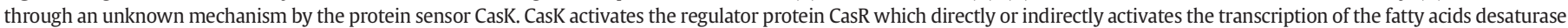

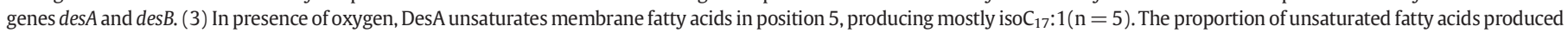

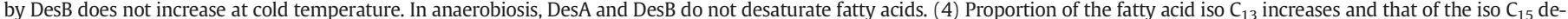

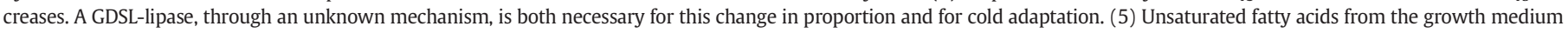

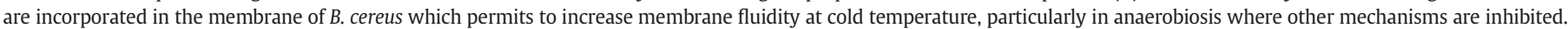

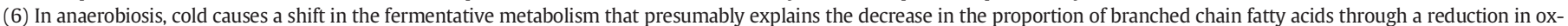
idized co-factors. (7) The increased membrane fluidity compensates the impact of cold and permits growth of the bacteria.

\subsubsection{Metabolism}

Cold temperature provoked a shift of glucose metabolism in B. cereus from glycolysis to the pentose phosphate pathway (Chung et al., 1976; Choma et al., 2000) and a transposon mutant in a gene coding for an enzyme of the pentose phosphate pathway had a reduced growth at low temperature (Broussolle et al., 2010). In absence of oxygen, cold also changed the fermentative metabolisms of $B$. cereus, reducing markedly ethanol production (De Sarrau et al., 2012). This altered the redox balance of the cell which could explain the very low synthesis of branch chain fatty acids in B. cereus grown in cold and anaerobiosis (Fig. 2b), a possible cause of the difficulty of the bacteria to grow in such conditions (de Sarrau et al., 2012).

\subsubsection{Sensing cold and regulation}

A two component, sensor-regulator system, CasKR, which deletion prevented growth at low temperature of $B$. cereus, was recently identified (Diomande et al., 2014). At low temperature, deletion of CasKR caused a reduction in the expression of the desaturase gene des $A$ and a concomitant reduction in the synthesis of fatty acids unsaturated in position 5 (Diomandé et al., 2015-in this issue). CasKR presumably contributes to cold adaptation in $B$. cereus by regulating the increase in membrane fluidity mediated by the unsaturation of fatty acids in position 5 (Fig. 2a). In B. subtilis the two component system DesKR, includes a sensor (DesK) inserted in the membrane that detects temperature downshifts through changes in the membrane thickness. Once activated DesK phosphorylates the regulator (DesR) that activates in turn the expression of the fatty acid desaturase (Aguilar et al., 2001; Cybulski et al., 2010). In contrast to DesK, the sensor protein CasK from B. cereus has no predicted transmembrane domain, therefore sensing cold may occur through a different mechanism in B. cereus (Fig. 2a).

\subsubsection{Diversity of cold adaptation among $B$. cereus sensu lato}

All $B$. cereus are not able to grow at refrigeration temperatures. B. cereus, together with Bacillus mycoides, Bacillus pseudomycoides, Bacillus anthracis, B. thuringiensis, Bacillus weihenstephanensis and Bacillus cytotoxicus form a group of very closely related species called B. cereus sensu lato (Guinebretiere et al., 2008, 2013). Its phylogenetic structure was resolved in seven groups (Guinebretiere et al., 2008; Tourasse et al., 2010) each having specific adaptations to temperature, with their minimum growth temperatures ranging from $4{ }^{\circ} \mathrm{C}$ to $20^{\circ} \mathrm{C}$. The phylogenetic structure of the $B$. cereus Group indicates the emergence through evolution of several cold adapted populations (Guinebretiere et al., 2008). 
Thermal DNA signatures have been identified in B. cereus sensu lato: one DNA sequence in the Cold Shock Protein A gene $\operatorname{csp} A$ (Francis et al., 1998) specific for one of the psychrotrophic phylogenetic groups (group VI containing the species B. mycoides and B. weihenstephanensis, Guinebretiere et al., 2008) and one rrs ribosomal DNA signature (Pruss et al., 1999) which abundance correlates with the minimum growth temperature of the phylogenetic groups (Guinebretiere et al., 2008). However it is not known if, and by which mechanisms, these DNA signatures improve cold adaptation of $B$. cereus.

The most thermophilic phylogenetic group (group VII corresponding to B. cytotoxicus), unable to grow below $20^{\circ} \mathrm{C}$ (Guinebretiere et al., 2008) lacks the genes of the two components sensor-regulator system CasKR, necessary for growth at low temperatures in B. cereus strains from other phylogenetic groups (Diomande et al., 2014). Phylogenetic group VII is also characterized by a particularly low amount of iso- $\mathrm{C}_{13}$ and high amount of iso- $C_{15}$ (Guinebretiere et al., 2013). A high iso$C_{13} /$ iso- $C_{15}$ ratio presumably contributes to cold adaptation in $B$. cereus as it increased when $B$. cereus from other phylogenetic groups were grown at low temperature (Haque and Russell, 2004; Brillard et al., 2010; De Sarrau et al., 2012) and did not increase in a mutant impaired for growth at low temperature (Brillard et al., 2010). It is possible that absence of CasKR and the low iso-C13/isoC-15 ratio contribute to the extreme thermotype of phylogenetic group VII within B. cereus sensu lato.

\subsubsection{Sporulation and cold adaptation of B. cereus}

Production of spores is an important survival strategy for $B$. cereus. Once adapted to cold, $B$. cereus produces spores which differ from those at optimal temperature for their lower heat resistance and more efficient germination (Planchon et al., 2011). Compared to spores produced at $30{ }^{\circ} \mathrm{C}$, spores produced at $10{ }^{\circ} \mathrm{C}$ had less iso branched chain fatty acids and more anteiso branched chain fatty acids: $16 \%$ iso- $C_{15}$ instead of $34 \%, 13 \%$ anteiso- $C_{15}$ instead of $7 \%$. In contrast to vegetative cells, spores produced at $10{ }^{\circ} \mathrm{C}$ versus $30{ }^{\circ} \mathrm{C}$ showed no increase in iso$\mathrm{C}_{13}$ and in the branched, monounsaturated fatty acid iso- $\mathrm{C}_{17}: 1$. Impact of cold during sporulation on spore fatty acids seems therefore very different from the impact of cold during vegetative growth.

\section{Using food components to survive under harsh conditions}

Several authors have described that food-borne pathogenic bacteria are able to survive better under extreme environmental conditions or to food preservation treatments when they are inoculated into certain foods or food-derived media than when laboratory media is used as treatment media (Waterman and Small, 1998; Alvarez-Ordóñez et al., 2009b). This suggests that microorganisms can benefit from the physico-chemical properties of foods or can use some food components or molecules to respond to situations of stress.

A number of studies have demonstrated a role for particular amino acids in the maintenance of intracellular $\mathrm{pH}$ homeostasis in Enterobacteriaceae under lethal acidic environments (Kieboom and Abee, 2006; Lee et al., 2007; Álvarez-Ordóñez et al., 2010b; Feehily and Karatzas, 2012). Arginine, lysine, and glutamate are among those amino acids used by inducible decarboxylase systems responsible for maintenance of intracellular $\mathrm{pH}$. The arginine decarboxylase system is composed by an arginine decarboxylase (AdiA) which converts arginine into agmatine in the cytoplasm with the consumption of a proton, an arginine/agmatine antiporter (AdiC) which expels agmatine from the cell in exchange for external arginine, and a transcriptional activator (AdiY) (Kieboom and Abee, 2006; Álvarez-Ordóñez et al., 2010b). Similarly, the lysine decarboxylase system is composed of a transcriptional regulator of the cadBA operon (CadC), a lysine decarboxylase enzyme (CadA), and a lysine-cadaverine antiporter ( $\mathrm{CadB}$ ). Under conditions of low external $\mathrm{pH}$ in the presence of lysine CadC acts both as a signal sensor and a transcriptional regulator which activates the transcription of the cadBA operon. Following induction, the enzyme CadA converts intracellular lysine to cadaverine with the consumption of a proton, thus increasing the intracellular pH. Subsequently, cadaverine is exchanged for extracellular lysine via the CadB antiporter (Park et al., 1996; Lee et al., 2007). The glutamate decarboxylase system (GAD) catalyses the decarboxylation of glutamate to $\gamma$-aminobutyrate (GABA) with the consumption of a proton. This is the first step of the GABA shunt pathway that leads to the production of succinate by the sequential actions of GABA-aminotransferase and succinic semialdehyde dehydrogenase. An antiporter system is usually present to couple the uptake of glutamate to the efflux of GABA (Feehily and Karatzas, 2012). Whereas the GAD system has been described as the most important mechanism of acid resistance in E. coli, it appears to be absent in other members of the Enterobacteriaceae such as S. Typhimurium that uses instead the arginine and lysine decarboxylase systems (Audia et al., 2001). The GAD system is also important for the acid resistance of the food-borne pathogen L. monocytogenes (Cotter et al., 2001; Karatzas et al., 2012).

The amino acids valine, leucine and isoleucine are precursors of the synthesis of branched fatty acids in bacteria. In presence of isoleucine B. subtilis increased markedly the proportion of anteiso branched fatty acids and reduced the proportion of iso branched fatty acids (Cybulski et al., 2002). This increases the membrane fluidity and permits cold adaption of $B$. subtilis, particularly under conditions at which fatty acids desaturation is not possible, as under anaerobic respiration (Beranova et al., 2010). Isoleucine facilitated, whereas leucine impaired, cold adaptation of $L$. monocytogenes (Zhu et al., 2005).

A recent study by Madeo et al. (2012) has evidenced the importance of thiamine to withstand lethal acid stress in L. monocytogenes. They reported that a mutant in the thiT gene, which encodes a thiamine uptake system, was highly sensitive to acid exposure and evidenced that thiamine-depleted cultures failed to produce significant concentrations of acetoin, consistent with the known thiamine dependence of acetolactate synthase, an enzyme of the 2,3-butanediol fermentation pathway required for acetoin synthesis from pyruvate. They suggested that as acetoin synthesis is a proton-consuming process, the acid sensitivity observed in thiamine-depleted cultures may be owing to an inability to produce acetoin. The 2,3-butanediol fermentation pathway consists of a three step conversion. First, two molecules of pyruvate from glycolysis are combined to $\alpha$ acetolactate by $\alpha$-acetolactate synthase ( $\alpha$-ALS). $\alpha$-Acetolactate is then decarboxylated to acetoin by $\alpha$-acetolactate decarboxylase $(\alpha$-ALD) and, finally, 2,3-butanediol can be formed by reduction of acetoin by 2,3-butanediol dehydrogenase (BDH) (Celińska and Grajek, 2009). The 2,3-butanediol fermentation pathway is often regarded as a strategy to avoid excessive and potentially lethal intracellular acidification (Vivijs et al., 2014). Evidence for this protective role was first reported for the pathogenic bacteria Vibrio cholerae, where inactivation of the genes encoding the $\alpha$-ALS and $\alpha$-ALD resulted in a growth defect in broth with $1 \%$ glucose due to enhanced medium acidification (Yoon and Mekalanos, 2006). Later on, similar findings were reported in other microorganisms, including A. hydrophila (Van Houdt et al., 2007; Moons et al., 2011).

Urea, which is present in various environments in which bacteria can be found including soil, food, and the human host, can also be used by microorganisms to counteract lethal acid $\mathrm{pH}$. Food-borne pathogens encounter urea upon their interaction with the human host: human saliva contains $2.3 \mathrm{mM}$ to $4.1 \mathrm{mM}$, and the human stomach contains approximately $4.8 \mathrm{mM}$. In addition, foods of animal origin generally contain urea; for example, milk contains $4.4 \mathrm{mM}$ to $6.4 \mathrm{mM}$ urea (Mols and Abee, 2008). Urease activity, which is present in various microorganisms, plays a prominent role in the pathogenesis of the gastric pathogen Helicobacter pylori, by allowing its survival to the low $\mathrm{pH}$ conditions of the stomach. Urea hydrolysis occurs in $H$. pylori inside the cytoplasm resulting in the production of $\mathrm{NH}_{3}$ that is immediately protonated to form $\mathrm{NH}_{4}^{+}$. This ammonium is then metabolized or effluxed because its presence within the cell is counterproductive to the goal of raising $\mathrm{pH}$ while maintaining cellular viability (Miller and Maier, 2014). Urease utilization clusters similar to those of $H$. pylori 
have been identified in the genome of various food-borne pathogenic bacteria, although an equivalent role of ureolytic activity in acid survival has not been convincingly demonstrated for them yet (e.g. Mols and Abee, 2008).

Another relevant example of the ability of microorganisms to use food components to withstand stress conditions is the use of carbohydrates, amino acids and other molecules as compatible solutes in the response to conditions of osmotic stress. Bacteria are known to react to environments of elevated osmolarity by means of a biphasic response, which involves the stimulation of potassium uptake (and its counter-ion glutamate) followed by a dramatic increase in the cytoplasmic concentration (by synthesis and/or uptake) of several so-called compatible solutes - trehalose, proline, ectoine, betaine, carnitine, and choline, among others (Sleator and Hill, 2002). These compatible solutes play a dual role in osmoregulating cells, helping to restore cell volume while also stabilizing protein structure and function under adverse environmental conditions (Sleator et al., 2003). In fact, several authors have demonstrated that their presence stimulates microbial growth at elevated osmolarity (mainly by inoculation in media with salt supplementation). Nevertheless, synthesis and/or uptake of compatible solutes can also protect bacterial cells against other forms of osmotic stress. For example, trehalose, a nonreducing disaccharide of glucose, plays a pivotal role in protection of bacteria against drying (Breeuwer et al., 2003). These authors reported that addition of trehalose to the growth medium of Cronobacter sakazakii, a particularly desiccation resistant bacterial species, improved its survival after drying. They also described that intracellular trehalose concentration was increased more than five-fold in stationary-phase C. sakazakii cells exposed to drying. Similarly, other compatible solutes have been shown to improve the survival of microorganisms to high hydrostatic pressure treatments (Smiddy et al., 2004). Smiddy and coauthors observed that addition of both betaine and L-carnitine to the treatment medium improved the barotolerance of $L$. monocytogenes and that betaine was more effective than L-carnitine in protection of the microbial cell from the detrimental effects of high hydrostatic pressure treatments. The uptake or synthesis of compatible solutes has also been shown to allow growth of microorganisms at low temperature (Hill et al., 2002). Indeed, a study by Wemekamp-Kamphuis et al. (2004) described that the addition of betaine or carnitine to the growth medium resulted in a significant increase of $L$. monocytogenes growth at low temperatures, with an associated betaine and carnitine accumulation. They also showed that single and multiple deletions of the known compatible solute transporters BetL, Gbu, and OpuC (involved in uptake of betaine and carnitine) significantly reduced growth of L. monocytogenes at low temperatures. Therefore, some natural components of foods or solutes added to foods may inadvertently promote the growth of food-borne pathogens under sub-lethal stress conditions of low temperature. For instance, Sleator et al. (2009) evaluated the growth of $L$. monocytogenes at $7{ }^{\circ} \mathrm{C}$ in two infant formula preparations that differed only by the presence or absence of L-carnitine $(1.5 \mathrm{mg} / 100 \mathrm{ml})$, and observed that L. monocytogenes grew faster in the formula with L-carnitine. They also described that the addition of L-carnitine to the formula that originally contained no L-carnitine resulted in a significant increase in the growth rate and final cell numbers of L. monocytogenes, demonstrating a role for L-carnitine in providing chill tolerance to L. monocytogenes.

Fatty acids present as phospholipids in the growth medium or foods are incorporated in the membrane of $B$. cereus. Whenever these fatty acids contain a high proportion of unsaturated fatty acids, this fluidifies the bacterial membrane and facilitates cold adaptation (Diomandé et al., 2015-in this issue, De Sarrau et al., 2013). In anaerobic conditions (Fig. 2b) that prevents the endogenous fatty acid desaturation by the bacterium (De Sarrau et al., 2013), or in aerobic conditions in a cold sensitive deletion mutant $(\Delta$ casK/R) (Diomandé et al., 2015-in this issue) incorporation of exogenous unsaturated fatty acids restore normal cold adaptation.
Impact on other stresses is not documented. Presence and nature of lipids should be more often considered when predicting the stress adaptation of pathogenic bacteria in foods.

\section{The balance between self-preservation and nutritional competence (SPANC)}

Acquisition of transient stress tolerance by bacteria is subject to a considerable cellular cost since it normally implicates large-scale host protection mechanisms involving several hundred cell components (e.g. proteins and stress-protectant metabolites) which accumulate to counteract the environmental challenges faced (Hengge-Aronis, 2002). Consequently, in return, high stress resistance is commonly accompanied by a reduction in the bacterial capacity to compete vegetatively for the utilization of nutrients present in the environment at low concentrations. Indeed, an inverse relationship between competitiveness and the resistance of strains to stresses has been described for various food-borne pathogens. This fact can be regarded as the balance between the processes of self-preservation and nutritional competence (SPANC balance) and is responsible for the heterogeneity in stress tolerance among bacterial species (Phan and Ferenci, 2013). One of the best known examples of a SPANC balance is the one driven by mutations in the general stress response regulator $r p o S$ (alternative sigma factor $\sigma^{38}$ or $\sigma^{S}$ ) in members of the Enterobacteriaceae family. Sigma factors are dissociable subunits of RNA polymerase that have a key role in the regulation of the production of specific sets of proteins under specific environmental conditions. The core of RNA polymerase consists of five subunits, but this form is unable to initiate transcription from promoters without a sigma factor (the sixth subunit). Sigma factors can bind to RNA polymerase, and this complex can recognize promoters and melt DNA, thus initiating transcription (Van Schaik and Abee, 2005). Most transcription events are mediated by the sigma factors $\sigma^{70}$ (in Gramnegative bacteria) and $\sigma^{\mathrm{A}}$ (in Gram-positive bacteria). However, under specific conditions, including exposure to stress, other sigma factors (i.e. alternative sigma factors) are activated and control the expression of specialized sets of genes (regulons) (Gruber and Gross, 2003). One of the best studied alternative sigma factors is the alternative sigma factor $\sigma^{S}(\mathrm{RpoS})$ of Gram-negative bacteria. RpoS is the master regulator of the general stress response in Gram-negative bacteria. While in rapidly growing cells levels of RpoS are low, exposure to many different stress conditions results in a rapid and strong RpoS induction, and a consequent transcription of numerous RpoS-dependent genes, many of them encoding gene products with stress-protective functions (Hengge-Aronis, 2002). Despite the critic importance of RpoS for cellular survival and protection under hostile environments, several studies have shown that the rpoS gene is located in a highly polymorphic segment of the bacterial chromosome (Ferenci, 2003, 2008). In addition, various authors have described the frequent isolation of rpoS defective natural isolates in different members of the Enterobacteriaceae family, including the food-borne pathogens E. coli (Waterman and Small, 1996; King et al., 2004; Bhagwat et al., 2006; Dong et al., 2009; Chiang et al., 2011; Alvarez-Ordóñez et al., 2013a), S. enterica (Robbe-Saule et al., 2003) and C. sakazakii (Alvarez-Ordóñez et al., 2012a). In the first comprehensive study on rpoS polymorphisms, Waterman and Small (1996) found that over $20 \%$ of 58 tested E. coli strains had mutations in the rpoS gene that were linked to a reduced stress tolerance. Subsequent studies on E. coli, Salmonella spp. and C. sakazakii have described similar percentages of isolates with truncated RpoS among field collections of microorganisms (Robbe-Saule et al., 2003; Chiang et al., 2011; Alvarez-Ordóñez et al., 2012a). The majority of rpoS mutations are loss-of-function mutations with little or no residual RpoS protein and include stop codons, deletions, and insertions as well as point mutations, although partial or attenuated rpoS mutations have also been described in other research articles. Most of those studies have reported a relationship between $r p o S$ status (intact vs truncated RpoS) or expression level and overall intraspecies variability in tolerance to a 
wide range of stress conditions (e.g. acid, alkaline, oxidative, osmotic, thermal, and HHP exposures). Maintenance of a defective or less active RpoS may appear paradoxical, as it is likely to affect cellular survival under harsh conditions. However, rpoS mutations have been shown to confer a selective advantage for the cell under certain conditions. For instance, Wang et al. (2010) have observed that rpoS mutations provide E. coli populations a strong fitness benefit under phosphate limitation. Similarly, King et al. (2004) reported that E. coli rpoS mutant strains are able to use more novel and alternative carbon sources for their growth than strains with a functional RpoS and show faster growth under limited-nutrients environments. Indeed, rpoS mutants of increased fitness have been shown to occur by natural selection in bacterial cultures maintained under carbon starvation or in the presence of non-preferred carbon sources (Zambrano et al., 1993; Dong et al., 2009; Alvarez-Ordóñez et al., 2013b). For example, growth on weak acids (e.g. succinate and acetate) strongly selects for rpoS mutations in laboratory E. coli strains (Chen et al., 2004; Spira et al., 2008). Likewise, a study by Alvarez-Ordóñez et al. (2013b) has shown that growth of C. sakazakii in a minimal medium supplemented with acetate can select for loss of RpoS, with a consequent reduction in stress tolerance. In addition, C. sakazakii rpoS mutants have been recently isolated by propagation in minimal medium supplemented with other non-preferred carbon sources such as succinate, fumarate and propionate (AlvarezOrdóñez et al., unpublished data). On the contrary, exposure to some food-related stresses can lead to increased RpoS activity, as shown by Vanlint et al. (2013) for HHP treatments. These authors reported that E. coli HHP-resistant variants obtained after several pressurization cycles showed a significant up-regulation of rpoS, although this phenotype did not stem from mutations in the rpoS locus. Therefore, it appears clear that selection for loss or gain of RpoS function may be an important adaptive mechanism to maximize bacterial growth or survival in complex natural environments.

\section{Consequences for food safety and future prospects}

Microorganisms dispose of a range of adaptive mechanisms that contribute to their fitness in changing stressful environments. Many specific stress responses have been described in a wide range of foodborne pathogenic bacteria, which allow them to respond to environmental signals by temporarily changing the patterns of gene expression or modulating the cellular structure or conformation. These adaptive stress responses are normally transient and highly energy demanding, and, for this reason, are not always beneficial for the cell. Indeed, selection for loss of key regulators of these transient stress responses can occur in complex bacterial populations in order to guarantee an improved fitness under specific environments. On the other hand, microorganisms can also enhance their chances of survival under stress conditions by increasing the generation of diversity at the population level. This can be achieved either by creating genetic diversity by a variety of mechanisms involving for example constitutive or transient adaptive mutations, or by revealing phenotypic diversity that remained dormant. On the long term, adaptation to some stressing conditions can be the driver of species evolution as shown by the emergence of cold tolerant groups within B. cereus.

Research studies following a direct evolution approach have shown that adaptive mutagenesis can occur upon recurrent exposure to lethal stress conditions. This phenomenon might lead to the generation and proliferation of stress hyper-resistant clonal variants in stressed populations. Nevertheless, it is still controversial whether such dispersion of hyper-resistant clonal variants actually occurs in foods and food processing environments. A study by Dlusskaya et al. (2011) suggests that this might be the case. Dlusskaya and co-authors tested the heat and acid resistance of $E$. coli reference strains and $E$. coli strains isolated from beef processing plants after steam and lactic acid decontamination interventions. They observed that heat resistance values of current slaughter plant isolates was around 100 times higher than those obtained for reference E. coli strains and E. coli isolates from live cattle, and that some plant isolates can survive cooking of ground beef to the recommended internal temperature of $71^{\circ} \mathrm{C}$.

Bacterial stress tolerance responses can also result in crossprotection against a wide variety of lethal exposures different from that inducing the adaptive response. Such cross-protection responses are particularly significant when minimal processing of foods is considered, where the imposition of one sub-lethal stress may lead to the induction of multiple stress responses that may reduce the efficacy of subsequent treatments, and must be considered when implementing new preservation technologies or processing regimes (Abee and Wouters, 1999; Yousef and Courtney, 2003; Wesche et al., 2009). Regarding this issue, the prediction of phenotypic behaviour using cellular indicators is a key area of research in the field of food-borne pathogens that in the near future will aid in the design and development of more efficient (novel combination) food preservation regimes or control strategies (Abee et al., 2011; Desriac et al., 2013). Quantitatively correlating microbial responses at molecular and phenotypic levels can assist the identification of cellular indicators for bacterial performance under stress conditions and under particular food preservation regimes. Den Besten et al. (2010) designed a framework for identifying cellular biomarkers for mild stress induced enhanced microbial robustness towards lethal stress conditions in B. cereus. These authors selected several candidate biomarkers (e.g. transcriptional regulators, enzymes, chaperones and proteases) by comparing the genome-wide transcriptome profiles of $B$. cereus upon exposure to mild stress conditions (heat, acid, salt and oxidative stress) and quantified all them at transcript, protein and/or activity level alongside with the stress induced robustness acquired towards lethal stress conditions. They were able to identify both short- and long-term biomarkers of bacterial tolerance responses towards lethal heat, acid and oxidative stresses. In particular, they found better predictive potential of enzyme activity and proteins compared to transcripts, with catalase activity and SigB protein levels showing the highest predictive quality. In previous sections of this review article we have identified two additional cellular components that could be used as indicators of bacterial robustness towards stress exposures, i.e. membrane fluidity for heat resistance and cold tolerance, and rpoS activity for bacterial resistance to oxidative, osmotic and acid stress among others in Enterobacteriaceae. Nevertheless, promising candidate-biomarkers could be genus, species or even strain specific, since the functional conservation of stress-related cellular factors differs in nature. Further investigations testing wide range of microorganisms under variable stress intensities will reveal how reliable those described biomarkers are. Systematic approaches will facilitate the identification of wide spectrum and narrow spectrum biomarkers which will aid the prediction of the history-dependent microbial behaviour in foods (Den Besten et al., 2010; Desriac et al., 2013).

Apart from conditioning the survival of pathogenic bacteria in foods and their resistance to food processing treatments, bacterial stress responses might also impact the disease-causing potential of bacterial strains and therefore the final outcome of the food-borne disease. There exists a controversy on whether bacterial responses to environmental stresses can modulate virulence (Gahan and Hill, 1999; Archer, 1996). It is known that some genetic systems involved in specific stress responses are the same as those associated with virulence during infection. Thus, the ability to deal successfully with environmental stresses would help (indirectly) bacterial virulence. Genes needed to withstand stress conditions in the environment (involved in ATR, oxidative stress, osmolarity stress) would help bacteria to access the gastrointestinal interface and eventually provoke virulence in the host, both types of genes being expressed in response to surrounding signals. Some studies have reported that adaptive responses to changing environments and foodrelated physical or chemical stresses (e.g. starvation, extreme temperatures, organic acids etc.) may affect the virulence of pathogenic bacteria 
(Gahan and Hill, 1999). Indeed, some stress response regulators (e.g. RpoS in Gram-negatives, $\sigma^{B}$ in Gram-positives) are also known to be involved in the regulation of pathogenicity traits of certain food-borne pathogens, which suggests that stress responses may be an important factor in potentiating the expression of particular virulence factors in vivo. The coordinated transcriptional regulation of virulence and stress response gene expression is very important for some foodborne pathogens, like L. monocytogenes, and this is shown in the joint involvement of $\operatorname{sig} B$ and $\operatorname{prf} A$. Experiments with $\operatorname{sig} B$ and $\operatorname{prf} A$ mutants suggest a regulatory overlap between the stress response and virulence transcriptional networks. Certain genes (involved in intracellular survival, spread and multiplication) are activated only by PrfA, while genes involved in the stress response only by $\operatorname{SigB}$, and genes with a role in virulence in the gastrointestinal interface are activated by both regulators (Kazmierczak et al., 2006; Zhang et al., 2011). Regulation of virulence involves activation and repression of many regulatory networks and mechanisms that we now begin to elucidate.

On the other hand, some studies are linking increased stress resistance with virulence attenuation of bacterial pathogens (Karatzas et al., 2007, 2008). Further research remains to be done on the effects of environmental stress and food preservation techniques on the virulence of food-borne pathogens in order to shed light into this conundrum.

It is also unclear whether environmental conditions can impact bacterial susceptibility to antibiotics and other antimicrobials. On one side antimicrobials themselves are growth-inhibiting stressors that often elicit protective responses in bacteria, thus provoking their own resistance-promoting responses. Cellular permeability to antibiotics is known to change in response to factors such as shifts in temperature, presence of specific inducers, reactive oxygen species, or specific metabolic signals (McMahon et al., 2007). Reduced susceptibility to antibiotics in response to environmental stresses may be mediated through modification of the lipopolysaccharide or other components of the cellular envelopes, or through enhanced expression of multiple efflux pumps that extrude the antibiotic once it has reached the cytoplasm decreasing the toxic activity (McMahon et al., 2007; Martínez and Rojo, 2011).

Exposure to stress can induce various degrees of cellular damage or injury depending on the intensity of the stress and the physiological state of individual cells within the population. Injured cells represent a challenge for traditional food microbiology analytical methods. Upon exposure to lethal stresses a fraction of the bacterial population may enter a non-culturable physiological state in which cells still remain metabolically active, retain their pathogenic properties and possess the ability to resuscitate under favourable circumstances. This is known as the viable but not culturable (VBNC) state (Ramamurthy et al., 2014). VBNC cells do not grow in classic preenrichment media used for detection of pathogenic bacteria in food and environmental samples and may therefore go undetected during routine monitoring programmes. However, subsequent cellular repair may allow for injury recovery and bacterial growth in foods. Future research must focus on the development of reliable analytical methods capable to detect and enumerate VBNC cells in foods. Such methodologies need to be incorporated into standardized detection and enumeration methodologies.

\section{Acknowledgements}

A. Alvarez-Ordóñez is a Starting Investigator Research Fellow funded by Science Foundation Ireland (SFI) under Grant Number 13/SIRG/2157. The financial contribution of the Spanish INIA (Plan Nacional I + D + I. Ref. RTA2011-00079-C02-02) is acknowledged.

\section{References}

Abee, T., Wouters, J.A., 1999. Microbial stress response in minimal processing. Int. J. Food Microbiol. 50, 65-91.
Abee, T., Wels, M., de Been, M., den Besten, H., 2011. From transcriptional landscapes to the identification of biomarkers for robustness. Microb. Cell Factories 10, S9.

Aguilar, P.S., Hernandez-Arriaga, A.M., Cybulski, L.E., Erazo, A.C., de Mendoza, D., 2001. Molecular basis of thermosensing: a two-component signal transduction thermometer in Bacillus subtilis. EMBO J. 20, 1681-1691.

Alvarez-Ordóñez, A., Fernández, A., López, M., Arenas, R., Bernardo, A., 2008. Modifications in membrane fatty acid composition of Salmonella Typhimurium in response to growth conditions and their effect on heat resistance. Int. J. Food Microbiol. 123, 212-219.

Alvarez-Ordóñez, A., Fernández, A., López, M., Bernardo, A., 2009a. Relationship between membrane fatty acid composition and heat resistance of acid and cold stressed Salmonella Senftenberg CECT 4384. Food Microbiol. 26, 347-353.

Alvarez-Ordóñez, A., Fernández, A., Bernardo, A., López, M., 2009b. Comparison of acids on the induction of an Acid Tolerance Response in Salmonella Typhimurium, consequences for food safety. Meat Sci. 81, 65-70.

Álvarez-Ordóñez, A., Halisch, J., Prieto, M., 2010a. Changes in Fourier transform infrared spectra of Salmonella enterica serovars Typhimurium and Enteritidis after adaptation to stressful growth conditions. Int. J. Food Microbiol. 142, 97-105.

Álvarez-Ordóñez, A., Fernández, A., Bernardo, A., López, M., 2010b. Arginine and lysine decarboxylases and the acid tolerance response of Salmonella Typhimurium. Int. J. Food Microbiol. 136, 278-282.

Alvarez-Ordóñez, A., Begley, M., Hill, C., 2012a. Polymorphisms in rpoS and stress tolerance heterogeneity in natural isolates of Cronobacter sakazakii. Appl. Environ. Microbiol. 78, 3975-3984.

Alvarez-Ordóñez, A., Prieto, M., Bernardo, A., Hill, C., López, M., 2012b. The acid tolerance response of Salmonella spp.: an adaptive strategy to survive in stressful environments prevailing in foods and the host. Food Res. Int. 45, 482-492.

Alvarez-Ordóñez, A., Alvseike, O., Omer, M.K., Heir, E., Axelsson, L., Holck, A., Prieto, M., 2013a. Heterogeneity in resistance to food-related stresses and biofilm formation ability among verocytotoxigenic Escherichia coli strains. Int. J. Food Microbiol. 161, 220-230.

Alvarez-Ordóñez, A., Begley, M., Hill, C., 2013b. Selection for loss of RpoS in Cronobacter sakazakii by growth in the presence of acetate as a carbon source. Appl. Environ. Microbiol. 79, 2099-2102.

Annous, B.A., Kozempel, M.F., Kurantz, M.J., 1999. Changes in membrane fatty acid composition of Pediococcus sp. strain NRRL B-2354 in response to growth conditions and its effect on thermal resistance. Appl. Environ. Microbiol. 65, 2857-2862.

Archer, D., 1996. Preservation microbiology and safety: evidence that stress enhances virulence and triggers adaptive mutations. Trends Food Sci. Technol. 7, 91-95.

Audia, J.P., Webb, C.C., Foster, J.W., 2001. Breaking through the acid barrier: an orchestrated response to proton stress by enteric bacteria. Int. J. Med. Microbiol. 291, 97-106.

Bearson, S.M.D., Bearson, B.L., Rasmussen, M.A., 2006. Identification of Salmonella enterica serovar Typhimurium genes important for survival in the swine gastric environment. Appl. Environ. Microbiol. 72, 2829-2836.

Beney, L., Gervais, P., 2001. Influence of the fluidity of the membrane on the response of microorganisms to environmental stresses. Appl. Microbiol. Biotechnol. 57, 34-42.

Beranova, J., Mansilla, M.C., de Mendoza, D., Elhottova, D., Konopasek, I., 2010. Differences in cold adaptation of Bacillus subtilis under anaerobic and aerobic conditions. J. Bacteriol. 192, 4164-4171.

Bhagwat, A.A., Tan, J., Sharma, M., Kothary, M., Low, S., Tall, B.D., Bhagwat, M., 2006. Functional heterogeneity of RpoS in stress tolerance of enterohemorrhagic Escherichia coli strains. Appl. Environ. Microbiol. 72, 4978-4986.

Breeuwer, P., Lardeau, A., Peterz, M., Joosten, H.M., 2003. Desiccation and heat tolerance of Enterobacter sakazakii. J. Appl. Microbiol. 95, 967-973.

Brillard, J., Jehanno, I., Dargaignaratz, C., Barbosa, I., Ginies, C., Carlin, F., Fedhila, S., Nguyen-the, C., Broussolle, V., Sanchis, V., 2010. Identification of Bacillus cereus genes specifically expressed during growth at low temperatures. Appl. Environ. Microbiol. 76, 2562-2573.

Broussolle, V., Pandiani, F., Haddad, N., Michaud, C., Carlin, F., Nguyen-the, C., Brillard, J., 2010. Insertional mutagenesis reveals genes involved in Bacillus cereus ATCC 14579 growth at low temperature. FEMS Microbiol. Lett. 306, 177-183.

Celińska, E., Grajek, W., 2009. Biotechnological production of 2,3-butanediol - current state and prospects. Biotechnol. Adv. 27, 715-725.

Chang, Y.Y., Cronan, J.E., 1999. Membrane cyclopropane fatty acid content is a major factor in acid resistance of Escherichia coli. Mol. Microbiol. 33, 249-259.

Charollais, J., Dreyfus, M., Iost, I., 2004. CsdA, a cold-shock RNA helicase from Escherichia coli, is involved in the biogenesis of 50 S ribosomal subunit. Nucleic Acids Res. 32, 2751-2759.

Chen, G., Patten, C.L., Schellhorn, H.E., 2004. Positive selection for loss of RpoS function in Escherichia coli. Mutat. Res. 554, 193-203.

Chiang, S.M., Dong, T., Edge, T.A., Schellhorn, H.E., 2011. Phenotypic diversity caused by differential RpoS activity among environmental Escherichia coli isolates. Appl. Environ. Microbiol. 77, 7915-7923.

Choma, C., Clavel, T., Dominguez, H., Razafindramboa, N., Soumille, H., Nguyen-the, C., Schmitt, P., 2000. Effect of temperature on growth characteristics of Bacillus cereus TZ415. Int. J. Food Microbiol. 55, 73-77.

Chung, B.H., Cannon, R.Y., Smith, R.C., 1976. Influence of growth temperature on glucosemetabolism of a psychrotrophic strain of Bacillus cereus. Appl. Environ. Microbiol. 31, 39-45.

Cifre, L.C., Alemany, M., de Mendoza, D., Altabe, S., 2013. Exploring the biosynthesis of unsaturated fatty acids in Bacillus cereus ATCC 14579 and functional characterization of novel acyl-lipid desaturases. Appl. Environ. Microbiol. 79, 6271-6279.

Cordin, O., Banroques, J., Tanner, N.K., Linder, P., 2006. The DEAD-box protein family of RNA helicases. Gene 367, 17-37.

Cotter, P.D., Gahan, C.G., Hill, C., 2001. A glutamate decarboxylase system protects Listeria monocytogenes in gastric fluid. Mol. Microbiol. 40, 465-475. 


\section{Version définitive du manuscrit publiée dans / Final version of the manuscript published in : International Journal of Food Microbiology (2015), Vol. 213, p. 99-109, DOI: 10.1016/j.ijfoodmicro.2015.06.004 Journal homepage : http://www.elsevier.com/locate/ijfoodmicro}

Cybulski, L.E., Albanesi, D., Mansilla, M.C., Altabe, S., Aguilar, P.S., de Mendoza, D., 2002 Mechanism of membrane fluidity optimization: isothermal control of the Bacillus subtilis acyl-lipid desaturase. Mol. Microbiol. 45, 1379-1388.

Cybulski, L.E., Martin, M., Mansilla, M.C., Fernandez, A., de Mendoza, D., 2010. Membrane thickness cue for cold sensing in a bacterium. Curr. Biol. 20, 1539-1544.

Daniel, I., Oger, P., Winter, R., 2006. Origins of life and biochemistry under high-pressure conditions. Chem. Soc. Rev. 35, 858-875.

de Jonge, R., Ritmeester, W.S., van Leusden, F.M., 2003. Adaptive responses of Salmonella enterica serovar Typhimurium DT104 and other S. Typhimurium strains and Escherichia coli 0157 to low pH environments. J. Appl. Microbiol. 94, 625-632.

de Sarrau, B., Clavel, T., Clerté, C., Carlin, F., Giniès, C., Nguyen-The, C., 2012. Influence of anaerobiosis and low temperature on Bacillus cereus growth, metabolism, and membrane properties. Appl. Environ. Microbiol. 78, 1715-1723.

de Sarrau, B., Clavel, T., Zwickel, N., Despres, J., Dupont, S., Beney, L., Tourdot-Marechal, R. Nguyen-the, C., 2013. Unsaturated fatty acids from food and in the growth medium improve growth of Bacillus cereus under cold and anaerobic conditions. Food Microbiol. 36, 113-122.

den Besten, H.M.W., Arvind, A., Gaballo, H.M.S., Moezelaar, R., Zwietering, M.H., Abee, T., 2010. Short- and long-term biomarkers for bacterial robustness: a framework for quantifying correlations between cellular indicators and adaptive behavior. PLoS One 5, e13746.

Desriac, N., Broussolle, V., Postollec, F., Mathot, A.-G., Sohier, D., Coroller, L., Leguerine, I., 2013. Bacillus cereus cell response upon exposure to acid environment: toward the identification of potential biomarkers. Front. Microbiol. 4, 284.

Diomande, S.E., Chamot, S., Antolinos, V., Vasai, F., Guinebretiere, M.H., Bornard, I., Nguyen-the, C., Broussolle, V., Brillard, J., 2014. The CasKR two-component system is required for the growth of mesophilic and psychrotolerant Bacillus cereus strains at low temperatures. Appl. Environ. Microbiol. 80, 2493-2503.

Diomandé, S.E., Nguyen-The, C., Abee, T., Tempelaars, M.H., Broussolle, V., Brillard, J., 2015. Involvement of the CasK/R two-component system in optimal unsaturation of the Bacillus cereus fatty acids during low-temperature growth. Int. J. Food Microbiol. http:// dx.doi.org/10.1016/j.ijfoodmicro.2015.04.043 (in this issue).

Dlusskaya, E.A., McMullen, L.M., Gänzle, M.G., 2011. Characterization of an extremely heat-resistant Escherichia coli obtained from a beef processing facility. J. Appl. Microbiol. 110, 840-849.

Dong, T., Chiang, S.M., Joyce, C., Yu, R., Schellhorn, H.E., 2009. Polymorphism and selection of rpoS in pathogenic Escherichia coli. BMC Microbiol. 9, 118.

Duforc, E.J., Smith, I.C., Jarrell, H.C., 1984. Role of cyclopropane moieties in the lipid properties of biological membranes: A2 H NMR structural and dynamical approach. Biochemistry 23, 2300-2309.

Fedhila, S., Msadek, T., Nel, P., Lereclus, D., 2002. Distinct clpP genes control specific adaptive responses in Bacillus thuringiensis. J. Bacteriol. 184, 5554-5562.

Feehily, C., Karatzas, K.A.G., 2012. Role of glutamate metabolism in bacterial responses towards acid and other stresses. J. Appl. Microbiol. 114, 11-24.

Ferenci, T., 2003. What is driving the acquisition of mutS and rpoS polymorphisms in Escherichia coli? Trends Microbiol. 11, 457-461.

Ferenci, T., 2008. The spread of a beneficial mutation in experimental bacterial populations: the influence of the environment and genotype of the fixation of rpoS mutations. Heredity 100, 446-452.

Foster, J.W., 2000. Microbial responses to acid stress. In: Storz, G., Hengge-Aronis, R. (Eds.), Bacterial Stress Responses. ASM Press, Washington, pp. 99-115.

Francis, K.P., Mayr, R., von Stetten, F., Stewart, G., Scherer, S., 1998. Discrimination of psychrotrophic and mesophilic strains of the Bacillus cereus group by PCR targeting of major cold shock protein genes. Appl. Environ. Microbiol. 64, 3525-3529.

Gahan, C.G.M., Hill, C., 1999. The relationship between acid stress responses and virulence in Salmonella typhimurium and Listeria monocytogenes. Int. J. Food Microbiol. 50, 93-100.

Grogan, D.W., Cronan, J.E., 1997. Cyclopropane ring formation in membrane lipids of bacteria. Microbiol. Mol. Biol. Rev. 61, 429-441.

Gruber, T.M., Gross, C.A., 2003. Multiple sigma subunits and the partitioning of bacterial transcription space. Annu. Rev. Microbiol. 57, 441-466.

Guinebretiere, M.H., Thompson, F.L., Sorokin, A., Normand, P., Dawyndt, P., Ehling-Schulz, M., Svensson, B., Sanchis, V., Nguyen-The, C., Heyndrickx, M., De Vos, P., 2008. Ecological diversification in the Bacillus cereus group. Environ. Microbiol. 10, 851-865.

Guinebretiere, M.H., Auger, S., Galleron, N., Contzen, M., De Sarrau, B., De Buyser, M.L. Lamberet, G., Fagerlund, A., Granum, P.E., Lereclus, D., De Vos, P., Nguyen-The, C., Sorokin, A., 2013. Bacillus cytotoxicus sp nov is a novel thermotolerant species of the Bacillus cereus group occasionally associated with food poisoning. Int. J. Syst. Evol. Microbiol. 63, 31-40.

Haque, M.A., Russell, N.J., 2004. Strains of Bacillus cereus vary in the phenotypic adaptation of their membrane lipid composition in response to low water activity, reduced temperature and growth in rice starch. Microbiology 150, 1397-1404.

Hardwick, S.W., Luisi, B.F., 2013. Rarely at rest RNA helicases and their busy contributions to RNA degradation, regulation and quality control. RNA Biol. 10, 56-70.

Hengge-Aronis, R., 2002. Signal transduction and regulatory mechanisms involved in control of the sigma(S) (RpoS) subunit of RNA polymerase. Microbiol. Mol. Biol. Rev. 66, 373-395.

Hill, C., Cotter, P.D., Sleator, R.D., Gahan, C.G.M., 2002. Bacterial stress response in Listeria monocytogenes: jumping the hurdles imposed by minimal processing. Int. Dairy J. 12, 273-283.

Hunger, K., Beckering, C.L., Wiegeshoff, F., Graumann, P.L., Marahiel, M.A., 2006. Coldinduced putative DEAD box RNA helicases CshA and CshB are essential for cold adaptation and interact with cold shock protein B in Bacillus subtilis. J. Bacteriol. 188, 240-248.

Iost, I., Dreyfus, M., 2006. DEAD-box RNA helicases in Escherichia coli. Nucleic Acids Res. 34, 4189-4197.
Jofré, A., Aymerich, T., Bover-Cid, S., Garriga, M., 2010. Inactivation and recovery of Listeria monocytogenes, Salmonella enterica and Staphylococcus aureus after high hydrostatic pressure treatments up to $900 \mathrm{MPa}$. Int. Microbiol. 13, 105-112.

Karatzas, K.A.G., Bennik, M.H.J., 2002. Characterization of a Listeria monocytogenes Scott A isolate with high tolerance to high hydrostatic pressure. Appl. Environ. Microbiol. 68, 3183-3189.

Karatzas, K.A.G., Valdramidis, V.P., Wells-Bennik, M.H.J., 2005. Contingency locus in ctsR of Listeria monocytogenes Scott A: a strategy for occurrence of abundant piezotolerant isolates within clonal populations. Appl. Environ. Microbiol. 71, 8390-8396.

Karatzas, K.A.G., Zervos, A., Tassou, C.C., Mallidis, C.G., Humphrey, T.J., 2007. Piezotolerant small-colony variants with increased thermotolerance, antibiotic susceptibility, and low invasiveness in a clonal Staphylococcus aureus population. Appl. Environ. Microbiol. 73, 1873-1881.

Karatzas, K.A.G., Hocking, P.M., Jørgensen, F., Mattick, K., Leach, S., Humphrey, T.J., 2008. Effects of repeated cycles of acid challenge and growth on the phenotype and virulence of Salmonella enterica. J. Appl. Microbiol. 105, 1640-1648.

Karatzas, K.A., Suur, L., O'Byrne, C.P., 2012. Characterization of the intracellular glutamate decarboxylase system: analysis of its function, transcription, and role in the acid resistance of various strains of Listeria monocytogenes. Appl. Envrion. Microbiol. 78, 3571-3579.

Kazmierczak, M.J., Wiedmann, M., Boor, K.J., 2006. Contributions of Listeria monocytogenes $\sigma^{B}$ and PrfA to expression of virulence and stress response genes during extra- and intracellular growth. Microbiology 152, 1827-1838.

Kieboom, J., Abee, T., 2006. Arginine-dependent acid resistance in Salmonella enterica serovar Typhimurium. J. Bacteriol. 188, 5650-5653.

Kim, B.H., Kim, S., Kim, H.G., Lee, J., Lee, I.S., Park, Y.K., 2005. The formation of cyclopropane fatty acids in Salmonella enterica serovar Typhimurium. Microbiology 151, 209-218.

King, T., Ishihama, A., Kori, A., Ferenci, T., 2004. A regulatory trade-off as a source of strain variation in the species Escherichia coli. J. Bacteriol. 186, 5614-5620.

Lee, Y.H., Kim, B.H., Kim, J.H., Yoon, W.S., Bang, S.H., Park, Y.K., 2007. CadC has a global translational effect during acid adaptation in Salmonella enterica serovar Typhimurium. J. Bacteriol. 189, 2417-2425.

Madeo, M., O'Riordan, N., Fuchs, T.M., Utratna, M., Karatzas, K.A., O'Byrne, C.P., 2012. Thiamine plays a critical role in the acid tolerance of Listeria monocytogenes. FEMS Microbiol. Lett. 326, 137-143.

Mansilla, M.C., Cybulski, L.E., Albanesi, D., de Mendoza, D., 2004. Control of membrane lipid fluidity by molecular thermosensors. J. Bacteriol. 186, 6681-6688.

Martínez, J.L., Rojo, F., 2011. Metabolic regulation of antibiotic resistance. FEMS Microbiol. Rev. 35, 768-789.

Mayr, B., Kaplan, T., Lechner, S., Scherer, S., 1996. Identification and purification of a family of dimeric major cold shock protein homologs from the psychrotrophic Bacillus cereus WSBC 10201. J. Bacteriol. 178, 2916-2925.

McMahon, M.A., Xu, J., Moore, J.E., Blair, I.S., McDowell, D.A., 2007. Environmental stress and antibiotic resistance in food-related pathogens. Appl. Environ. Microbiol. 73, 211-217.

Metselaar, K.I., den Besten, H.M.W., Abee, T., Moezelaar, R., Zwietering, M.H., 2013. Isolation and quantification of highly acid resistant variants of Listeria monocytogenes. Int. J. Food Microbiol. 166, 508-514.

Miller, E.F., Maier, R.J., 2014. Ammonium metabolism enzymes aid Helicobacter pylori acid resistance. J. Bacteriol. 196, 3074-3081.

Mols, M., Abee, T., 2008. Role of ureolytic activity in Bacillus cereus nitrogen metabolism and acid survival. Appl. Environ. Microbiol. 74, 2370-2378.

Moons, P., Van Houdt, R., Vivijs, B., Michiels, C.W., Aertsen, A., 2011. Integrated regulation of acetoin fermentation by quorum sensing and $\mathrm{pH}$ in Serratia plymuthica RVH1. Appl. Environ. Microbiol. 77, 3422-3427.

Pandiani, F., Brillard, J., Bornard, I., Michaud, C., Chamot, S., Nguyen-the, C. Broussolle, V., 2010. Differential involvement of the five RNA helicases in adaptation of Bacillus cereus ATCC 14579 to low growth temperatures. Appl. Environ. Microbiol. 76, 6692-6697.

Pandiani, F., Chamot, S., Brillard, J., Carlin, F., Nguyen-the, C., Broussolle, V., 2011. Role of the five RNA helicases in adaptive response of Bacillus cereus ATCC 14579 cells to temperature, pH and oxidative stress. Appl. Environ. Microbiol. 77, 5604-5609.

Park, Y.K., Bearson, B., Bang, S.H., Bang, I.S., Foster, J.W., 1996. Internal pH crisis, lysine decarboxylase and the acid tolerance response of Salmonella typhimurium. Mol. Microbiol. 20, 605-611.

Phan, K., Ferenci, T., 2013. A design-constraint trade-off underpins the diversity in ecologically important traits in species Escherichia coli. ISME J. 7, 2034-2043.

Planchon, S., Dargaignaratz, C., Levy, C., Ginies, C., Broussolle, V., Carlin, F., 2011. Spores of Bacillus cereus strain KBAB4 produced at 10 degrees $C$ and 30 degrees $C$ display variations in their properties. Food Microbiol. 28, 291-297.

Pruss, B.M., Francis, K.P., von Stetten, F., Scherer, S., 1999. Correlation of 165 ribosomal DNA signature sequences with temperature-dependent growth rates of mesophilic and psychrotolerant strains of the Bacillus cereus group. J. Bacteriol. 181, 2624-2630.

Ramamurthy, T., Ghosh, A., Pazhani, G.P., Shinoda, S., 2014. Current perspectives on viable but non-culturable (VBNC) pathogenic bacteria. Front. Public Health 2, 103.

Rando, O.J., Verstrepen, K.J., 2007. Timescales of genetic and epigenetic inheritance. Cell 128, 655-668.

Robbe-Saule, V., Algorta, G., Rouilhac, I., Norel, F., 2003. Characterization of the RpoS status of clinical isolates of Salmonella enterica. Appl. Environ. Microbiol. 69, 4352-4358.

Sampathkumar, B., Khachatourians, G.G., Korber, D.R., 2004. Treatment of Salmonella enterica serovar Enteritidis with a sublethal concentration of trisodium phosphate or alkaline $\mathrm{pH}$ induces thermotolerance. Appl. Environ. Microbiol. 70, 4613-4620.

Sleator, R.D., Hill, C., 2002. Bacterial osmoadaptation: the role of osmolytes in bacterial stress and virulence. FEMS Microbiol. Rev. 26, 49-71. 
Version définitive du manuscrit publiée dans / Final version of the manuscript published in :

International Journal of Food Microbiology (2015), Vol. 213, p. 99-109, DOI: 10.1016/j.ịfoodmicro.2015.06.004

Journal homepage : http://www.elsevier.com/locate/ijfoodmicro

Sleator, R.D., Gahan, C.G.M., Hill, C., 2003. A postgenomic appraisal of osmotolerance in Listeria monocytogenes. Appl. Environ. Microbiol. 69, 1-9.

Sleator, R.D., Banville, N., Hill, C., 2009. Carnitine enhances the growth of Listeria monocytogenes in infant formula at $7{ }^{\circ} \mathrm{C}$. J. Food Prot. 72, 1293-1295.

Smiddy, M., Sleator, R.D., Patterson, M.F., Hill, C., Kelly, A.L., 2004. Role for compatible solutes glycine betaine and L-carnitine in listerial barotolerance. Appl. Environ. Microbiol. 70, 7555-7557.

Spira, B., Hu, X., Ferenci, T., 2008. Strain variation in ppGpp concentration and RpoS levels in laboratory strains of Escherichia coli K-12. Microbiology 154, 2887-2895.

Stenfors Arnesen, L.P., Fagerlund, A., Granum, P.E., 2008. From soil to gut: Bacillus cereus and its food poisoning toxins. FEMS Microbiol. Rev. 32, 579-606.

Tourasse, N.J., Økstad, O.A., Kolstø, A.B., 2010. HyperCAT: an extension of the SuperCAT database for global multi-scheme and multi-datatype phylogenetic analysis of the $\mathrm{Ba}$ cillus cereus group population. Database baq017.

Van Boeijen, I.K.H., Chavaroche, A.A.E, Valderrama, W.B., Moezelaar, R. Zwietering, M.H Abee, T., 2010. Population diversity of Listeria monocytogenes LO28: phenotypic and genotypic characterization of variants resistant to high hydrostatic pressure. Appl. Environ. Microbiol. 76, 2225-2233.

Van Boeijen, I.K.H., Francke, C., Moezelaar, R., Abee, T., Zwietering, M.H., 2011. Isolation of highly heat-resistant Listeria monocytogenes variants by use of a kinetic modelingbased sampling scheme. Appl. Environ. Microbiol. 77, 2617-2624.

Van Houdt, R., Aertsen, A., Michiels, C.W., 2007. Quorum-sensing-dependent switch to butanediol fermentation prevents lethal medium acidification in Aeromonas hydrophila AH-1 N. Res. Microbiol. 158, 379-385.

van Schaik, W., Abee, T., 2005. The role of $\sigma^{B}$ in the stress response of Gram-positive bacteria-targets for food preservation and safety. Curr. Opin. Biotechnol. 16, 218-224.

Vanlint, D., Mitchell, R., Bailey, E., Meersman, F., McMillan, P.F., Michiels, C.W., Aertsen, A., 2011. Rapid acquisition of Gigapascal-high pressure resistance by Escherichia coli. MBio 2 (e00130-10)

Vanlint, D., Rutten, N., Michiels, C.W., Aertsen, A., 2012. Emergence and stability of highpressure resistance in different food-borne pathogens. Appl. Environ. Microbiol. 78, 3234-3241.

Vanlint, D., Rutten, N., Govers, S.K., Michiels, C.W., Aertsen, A., 2013. Exposure to high hydrostatic pressure rapidly selects for increased RpoS activity and general stressresistance in Escherichia coli 0157:H7. Int. J. Food Microbiol. 163, 28-33.

Vivijs, B., Moons, P., Geeraerdb, A.H., Aertsen, A., Michiels, C.W., 2014. 1,2-Butanediol fermentation promotes growth of Serratia plymuthica at low $\mathrm{pH}$ but not survival of extreme acid challenge. Int. J. Food Microbiol. 175, 36-44.
Wang, L., Spira, B., Zhou, Z., Feng, L., Maharjan, R.P., Li, X., Li, F., McKenzie, C., Reeves, P.R., Ferenci, T., 2010. Divergence involving global regulatory gene mutations in an Escherichia coli population evolving under phosphate limitation. Gen. Biol. Evol. 2, 478-487.

Waterman, S.R., Small, P.L.C., 1996. Characterization of the acid resistance phenotype and rpoS alleles of Shiga-like toxin-producing Escherichia coli. Infect. Immun. 64, 2808-2811.

Waterman, S.R., Small, P.L.C., 1998. Acid-sensitive enteric pathogens are protected from killing under extremely acidic conditions of $\mathrm{pH} 2.5$ when they are inoculated onto certain solid food sources. Appl. Environ. Microbiol. 64, 3882-3886.

Wemekamp-Kamphuis, H.H., Wouters, J.A., de Leeuw, P.P., Hain, T., Chakraborty, T., Abee, T., 2004. Identification of sigma factor $\sigma^{B}$-controlled genes and their impact on acid stress, high hydrostatic pressure, and freeze survival in Listeria monocytogenes EGDe. Appl. Environ. Microbiol. 70, 3457-3466.

Wesche, A.M., Gurtler, J.B., Marks, B.P., Ryser, E.T., 2009. Stress, sublethal injury, resuscitation, and virulence of bacterial foodborne pathogens. J. Food Prot. 72, 1121-1138.

Yoon, S.S., Mekalanos, J.J., 2006. 2,3-Butanediol synthesis and the emergence of the Vibrio cholerae El Tor biotype. Infect. Immun. 74, 6547-6556.

Yousef, A.E., Courtney, P.D., 2003. Basics of stress adaptation and implications in newgeneration foods. In: Yousef, A.E., Juneja, V.J. (Eds.), Microbial Stress Adaptation and Food Safety. CRC Press, Boca Raton, FL, pp. 1-30.

Zambrano, M.M., Siegele, D.A. Almiron, M. Tormo, A, Kolter, R., 1993. Microbial competition: Escherichia coli mutants that take over stationary phase cultures. Science 259, $1757-1760$

Zeng, X., Birrien, J.L., Fouquet, Y., Cherkashov, G., Jebbar, M., Querellou, J., Oger, P., Cambon-Bonavita, M.A., Xiao, X., Prieur, D., 2009. Pyrococcus $\mathrm{CH} 1$, an obligate piezophilic hyperthermophile: extending the upper pressure-temperature limits for life. ISME J. 3, 873-876.

Zhang, Q., Feng, Y., Deng, L., Feng, F., Wang, L., Zhou, Q., Luo, Q., 2011. SigB plays a major role in Listeria monocytogenes tolerance to bile stress. Int. J. Food Microbiol. 145, 238-243.

Zhu, K., Ding, X., Julotok, M., Wilkinson, B.J., 2005. Exogenous isoleucine and fatty acid shortening ensure the high content of anteiso-C-15: 0 fatty acid required for lowtemperature growth of Listeria monocytogenes. Appl. Environ. Microbiol. 71, 8002-8007. 